\title{
MHD flow over a moving flat plate with a step change in the magnetic field
}

Acta Mechanica 116, $235-238$ (1996)

T. Y. Na, Dearborn, Michigan, and I. Pop, Cluj, Romania

Due to a remark by Dr. Kumaran, Department of Mathematics and Computational Applications, Regional Engineering College, Tiruchirappalli-620015, India, the model given in the above cited paper works for $x<x_{0}(=1)$ only. This is obvious from Fig. 2.

Authors' addresses: T.-Y. Na, Department of Mechanical Engineering, University of Michigan - Dearborn, Dearborn, MI 48128, U. S. A.; and I. Pop, Faculty of Mathematics, University of Cluj, R-3400 Cluj, CP 253, Romania

Verleger: Springer-Verlag KG, Sachsenplatz 4-6, A-1201 Wien. - Herausgeber: Prof. Dipl.-Ing. Dr. Hans Troger und Prof. Dipl.-Ing. Dr. Franz Ziegler, beide Technische Universität, Karlsplatz 13, A-1040 Wien. - Redaktion: Karlsplatz 13, A-1040 Wien. - Hersteller: Druckerei zu Altenburg GmbH, D-04600 Altenburg - Verlagsort: Wien. - Herstellungsort: Altenburg. - Printed in Germany. 